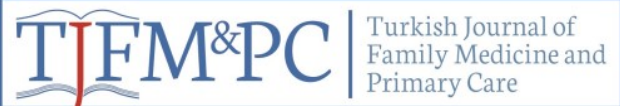

Original Research / Özgün Araştırma

\title{
The Relationship Between Adherence to Medication and Quality of Life and Health Perception in Hypertensive Patients
}

\author{
Hipertansiyon Hastalarında İlaç Tedavisine Uyumun Yaşam Kalitesi ve Sağlık \\ Algısıyla İlişkisi
}

Nilüfer Emre ${ }^{* 1}$, Tamer Edirne ${ }^{l}$, Aysun Özşahin ${ }^{1}$, Nilgün Çoban ${ }^{2}$, Aybüke Yanık Barışkan ${ }^{1}$

\begin{abstract}
Introduction: Medication adherence is an important component of disease management in the treatment of hypertension. The purpose of this study is to examine the relationship between medication adherence, quality of life and health perception in patients with hypertension. Method: This descriptive-cross-sectional study was performed in patients diagnosed with hypertension in a family health center in the city center of Denizli. In collecting data, sociodemographic characteristics, Hypertension Compliance Assessment Scale, quality of life scale and health perception scale were used. Results: The mean age of 117 patients who participated in the study was $62.85 \pm 9.29$, and $55.6 \%$ were women. The mean score of the participants' compliance to drug treatment scale was $3.98 \pm 1.73$ and $93.2 \%$ of them were in compliance with drug treatment. The mean health perception score of the participants was $49.76 \pm 6.50$ and a negative correlation was found between the health perception score and the drug treatment compliance score $(\mathrm{r}=-0.211 ; \mathrm{p}=0.023)$. The summary score of physical components of the quality of life subscales was $43.59 \pm 5.69$; The summary mean score of mental components was $47.10 \pm 6.62$. No correlation was found between drug treatment compliance score and quality of life subscales. No correlation was found between drug treatment compliance score and quality of life subscales. In addition, statistically significant blood pressure of those with good compliance with medication was under control ( $\mathrm{p}=0.003$ ). Conclusion: It was determined that the patients' compliance to the treatment affects their health perceptions but there is no relation with the quality of life. In addition, blood pressure values of patients with high compliance with medication were under control, and home blood pressure measurements were found to increase drug compliance.
\end{abstract}

Keywords: hypertension, medication adherence, quality of life, health, perception

\section{ÖZET}

Giriş: Hipertansiyon tedavisinde ilaç uyumu, hastalık yönetiminin önemli bir bileşenidir. Çalışmamızın amacı, hipertansiyon tanısı olan hastalardaki ilaç uyumunun, yaşam kalitesi ve sağlık algısıyla ilişkisini incelemektir. Yöntem: Tanımlayıcı-kesitsel nitelikte olan bu çalışma, Denizli il merkezinde bulunan bir aile sağlığı merkezinde, hipertansiyon tanısı almış hastalarda yapılmıştır. Verilerin toplanmasında, sosyodemografik özellikler, antihipertansif ilaç uyum ölçeği, yaşam kalitesi ölçeği ve sağlık algısı ölçeği kullanılmıştır. Bulgular: Çalışmaya

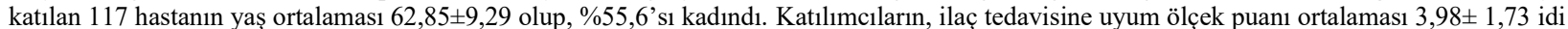
ve \%93,2'si ilaç tedavisine uymaktaydı. Katılımcıların sağlık algısı ortalama puanı 49,76 $\pm 6,50$ idi ve sağlık algısı puanı ile ilaç tedavisine uyum puanı arasında negatif yönde zayıf düzeyde ilişki bulunmuștur $(\mathrm{r}=-0,211 ; \mathrm{p}=0,023)$. Yaşam kalitesi alt ölçeklerinden fiziksel bileșenlerin özeti

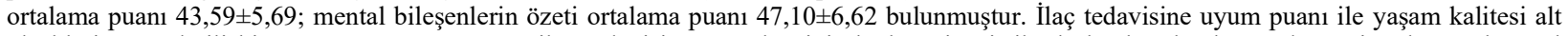
ölçekleri arasında ilişki saptanamamıştır. Ayrıca ilaç tedavisine uyumları iyi olanların istatistiksel olarak anlamlı oranda tansiyonlarının kontrol altında olduğu tespit edilmiştir ( $\mathrm{p}=0,003$ ). Sonuç: Çalışmamızda, hastaların ilaç tedavisine uyumunu, sağlık algısının etkilediği ancak yaşam kalitesiyle ilişkili olmadığı gösterilmiştir. Ayrıca ilaç tedavisine uyumu iyi olan hastaların tansiyon değerleri kontrol altındaydı ve evde tansiyon ölçümlerinin de ilaç uyumunu artırdı̆̆ı tespit edilmiştir

Anahtar kelimeler: hipertansiyon, tedavi uyumu, yaşam kalitesi, sağlik, kabul

Received date / Geliş tarihi: 24.04.2020, Accepted date / Kabul tarihi: 17.06.2020

${ }^{1}$ Pamukkale Üniversitesi, Aile Hekimliği Anabilim Dalı, Denizli-TÜRKIYYE.

${ }^{2}$ Şifabul Aile Sağlığı Merkezi , Denizli

*Address for Correspondence / Yazışma Adresi: Nilüfer Emre, Pamukkale Üniversitesi Tıp Fakültesi, Kınıklı yerleşkesi, Aile Hekimliği

Anabilim Dalı Pamukkale/Denizli-TÜRKIYE.

E-mail: nilemre83@gmail.com

Emre ve ark., Hipertansiyon Hastalarında İlaç Tedavisine Uyumun Yaşam Kalitesi ve Sağlık Algısıyla İlişkisi. TJFMPC, 2020;14(3): 436-442.

DOI: $10.21763 /$ tjfmpc.725974 


\section{GíRiş}

Hipertansiyon (HT), toplumda yaygınlığı giderek artan bir hastalık ve dünya çapında kardiyovasküler hastalıklar ve erken ölümler için önlenebilir bir risk faktörüdür. 2014 yılında dünya genelinde erişkinlerde hipertansiyonun küresel sıklığ1 yaklaşık \%22 olarak tespit edilmiştir. ${ }^{1,2}$ Ülkemizde yapılan Türk Hipertansiyon Prevalans (PatenT2) raporuna göre, hipertansiyonun görülme sıklığ1 $\%$ 30,3 olarak bildirilmiştir. ${ }^{3}$ Ayrıca ülkemizde yapılan hipertansiyon insidans çalışmasına göre de 4 yıllık hipertansiyon insidansı \% 21,4 olup; 65 yaş üstü bireylerde bu oran \% 43,3 olarak bulunmuştur. ${ }^{4}$ Yüksek kan basıncının büyük bir kardiyovasküler hastalık yükü ve erken ölüm ile ilişkisi olduğu gibi, kronik böbrek hastalığı (KBH) ve son dönem böbrek hastalığı için de güçlü bir bağımsız risk faktörü olduğu bildirilmiştir. Ayrıca iskemik ve hemorajik inmenin nedenleri arasında da yer almaktadır. ${ }^{1}$

Antihipertansif ilaçların yaygın kullanımı nedeniyle, küresel olarak ortalama kan basıncının son yirmi yılda sabit kaldığı, hatta biraz azaldı ̆̆ bildirilmektedir. ${ }^{1}$ Hipertansiyon tedavisinde ilaç uyumu, hastalık yönetiminin önemli bir bileşenidir. Tedavide başarılı olabilmek ancak tedaviye uyum ile sağlanabilmektedir. Tedaviye uyum, hastanın kontrollerini aksatmaması, yaşam tarzı değişiklikleri ve ilaç kullanımına ilişkin uyum ile gerçekleşmektedir. Ancak ilaç uyumu tüm sürecin bir aşamasıdır. Bununla birlikte yaşam kalitesi de, hastanın kronik hastalıklarını yönetme yeteneğini etkileyebilecek ve tek bir faktöre bağlı olmayan karmaşık psikososyal özelliklerle çevrili bir durumdur. Olguların çoğunda, hasta kendi davranışlarını gözlemler ve bu davranışın mevcut sağlık durumlarını nasıl etkilediğini değerlendirir. ${ }^{5,6}$ Tedavi sürecinde bir diğer durumsa sağlık algısıdır. Sağlık alg1sı, bireyin öz bakım sorumluluğunu almasını sağlayarak, kendi sağlığı ile ilgili doğru kararlar almasına yardımcı olur. ${ }^{7}$ Sağlık ve hastalık hakkındaki hasta inançları, ilaç uyumunun önemli bir yordayıcısıdır. ${ }^{8}$ Sonuçta hipertansiyon tedavisinde ilaç uyumunun önemli bir yeri vardır. Antihipertansif ilaç uyumunun, kardiyovasküler morbidite ve mortaliteyi azaltabilecek, optimal kan basıncı kontrolü için önemli bir faktör olduğu belirtilmektedir. ${ }^{9} \quad \mathrm{Bu}$ çalışmamızın amacı, hipertansiyon tanılı hastalarda ilaç tedavilerine uyumun yaşam kalitesi ve sağlık algısı ile ilişkisini incelemektir.

\section{YÖNTEM}

Araştırma tanımlayıcı kesitsel tipte olup, Denizli il merkezinde bulunan bir aile sağlığı merkezinde, Ocak-Mart 2020 tarihleri arasında yapıld1. Aile sağlığı merkezine başvuran, araştırmamıza gönüllü katılmayı kabul eden, 18 yaş üzeri ve en az 3 aydır hipertansiyon tanısı olan hastalar çalışmaya alınmıştır. Belirgin zihinsel anormallik, psikolojik bozukluk ve bilişsel bozukluk olanlar, fiziksel yeti yitimine bağlı engellik durumu olanlar çalışma dişı bırakılmıştır Çalışma öncesi, Pamukkale Üniversitesi Tıp Fakültesi Girişimsel Olmayan Klinik Araştırmalar Etik Kurulu'ndan 07.05.2019 tarih ve 09 sayılı kurul onayı alınmıştır. Katılımcılara sosyodemografik özelliklerle birlikte literatür taranarak oluşturulan sorular ve antihipertansif ilaç uyumu açısından ilaç uyum ölçeği, yaşam kalitesini değerlendirmek için yaşam kalitesi ölçeği (SF-12) ve sağlık algısını değerlendirmek için sağlık algısı ölçeği yüz yüze görüşme tekniğiyle uygulanmıştır. Buna ek olarak tüm katılımcılara uygun oturma pozisyonunda 5 dakika bekleme sonrası, \pm 4 sapma oranı ile kalibre edilmiş elektronik tansiyon aleti ile ardışık $2 \mathrm{kez}$ ölçüm yapılmıştır. Çalışmamızda, kan basıncı hedef değeri 140/90 mmHg'nın altı olarak alınmıştır. Ancak eşlik eden diyabetes mellitus ve/veya böbrek yetmezliği olması durumunda 130/80 mmHg'nın altı olarak kabul edilmiştir. Ayrica hastalara ev tansiyon aletleriyle (kalibrasyon durumları bilinmemekte) ölçüm yapılıp yapılmadığı sorgulanmıştır.

Veriler SPSS 21 paket programiyla analiz edilmiştir. Sürekli değişkenler ortalama \pm standart sapma ve kategorik değişkenler sayı ve yüzde olarak verilmiştir. Bağımsız grup farklılıkların karşılaştırılmasında parametrik test varsayımları sağlanamadığından, Mann-Whitney $U$ testi ve Kruskal Wallis Varyans Analizi kullanılmıştır. Ayrıca sürekli değişkenlerin arasındaki ilişkiler, Spearman analiziyle ve kategorik değişkenler arasındaki farklılıklar ise $\mathrm{Ki}$ kare analizi ile incelenmiştir. İstatistiksel anlamlılık düzeyi $\mathrm{p}<0,05$ olarak alınmıştır.

\section{Veri Toplama Araçları}

Antihipertansif ilaç Tedavisine uyum ölçeği: Morisky ve arkadaşları tarafından geliştirilen bu ölçek, 2006 yılında Demirezen tarafından Türk toplumuna uyarlanmış ve ölçeğin Cronbach $\alpha$ değeri 0,82 olarak bulunmuştur. Ölçek dokuz sorudan oluşmaktadır. İlk 8 sorusu "Evet" ve "Hayır" olarak cevaplandırılmakta olup, dokuzuncu soru her bir madde için 1. "hiç/nadiren", 2. "arasira", 3. "bazen", 4. "genellikle", 5. "her zaman" şıklarından oluşmaktadır. Ölçek toplam puanı 1-13 arasında değerlendirilmektedir. ${ }^{11,12}$

Sağlık Algısı Ölçeği: Ölçek Diamond ve ark.'ları tarafından 2007 yılında geliştirilmiş olup, Kadıŏlu ve ark. tarafından Türkçe geçerlilik ve güvenilirliği yapılmıştır. Olumlu ve olumsuz ifadelerin yer aldığ 1 toplam 15 soru ve beşli likert 
tipi bir ölçektir. Ölçekte toplam puan 15-75 arasında değerlendirilmektedir. ${ }^{13}$

Yaşam kalitesi ölçeği (SF-12): SF-36 yaşam kalitesi anketinin kısa versiyonu, iki alt ölçekten ve 12 maddeden oluşan SF-12 ölçeğidir. Fiziksel bileşenlerin özeti (FBÖ) ve mental bileşenlerin özeti (MBÖ) olan iki alt ölçek; fiziksel işlevsellik, fiziksel rol, ağrı, genel sağlık, duygusal rol, mental sağlık, sosyal işlevsellik ve canlılık gibi bileşenlerden oluşmaktadır. ${ }^{14,15}$

\section{BULGULAR}

Çalışmaya 117 kişi katılmıştır. Katılanların yaş ortalaması $62,85 \pm 9,29$ olarak tespit edilmiştir. \%55,6's1 kadın ve \%81,2'si evlidir. Katılımcıların

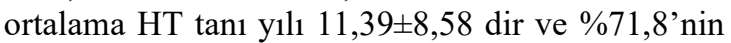
ailesinde HT öyküsü mevcuttur. Tablo 1'de katılımcıların sosyo-demografik özellikleri ve hipertansiyona ilişkin özellikleri verilmiştir.

Katılımcıların, ölçülen tansiyon değerleri açısından \%78,6'sının ( $\mathrm{n}=92)$ tansiyonu kontrol altında bulunmuştur. Ayrıca ilaç tedavisine uyum \%93,2 ( $\mathrm{n}=109)$ hastada iyi olarak tespit edilmiştir. İlaç tedavisine uyumu iyi olanlarda, tansiyon kontrol altında olma oranı istatistiksel olarak anlamlı düzeyde yüksek bulunmuştur $(p=0,003)$.

\begin{tabular}{|c|c|c|}
\hline Değişkenler & $\mathrm{n}$ & $\%$ \\
\hline Yaş & $62,85 \pm 9,29$ & \\
\hline $\begin{array}{l}\text { Cinsiyet } \\
\text { Kadın } \\
\text { Erkek }\end{array}$ & $\begin{array}{l}65 \\
52\end{array}$ & $\begin{array}{l}55,6 \\
44,4\end{array}$ \\
\hline $\begin{array}{l}\text { Medeni durum } \\
\text { Evli } \\
\text { Bekar }\end{array}$ & $\begin{array}{l}95 \\
22 \\
\end{array}$ & $\begin{array}{l}81,2 \\
18,8\end{array}$ \\
\hline $\begin{array}{l}\text { Eğitim durumu } \\
\text { İlkokul } \\
\text { Lise } \\
\text { Yükseklisans/üniversite } \\
\end{array}$ & $\begin{array}{l}73 \\
27 \\
17\end{array}$ & $\begin{array}{l}62,4 \\
23,1 \\
14,5\end{array}$ \\
\hline $\begin{array}{l}\text { Meslek } \\
\text { Ev hanımı } \\
\text { Emekli } \\
\text { Çalışan } \\
\end{array}$ & $\begin{array}{l}40 \\
59 \\
18\end{array}$ & $\begin{array}{l}34,2 \\
50,4 \\
15,4\end{array}$ \\
\hline $\begin{array}{l}\text { Gelir durumu } \\
1000-2000 \mathrm{tl} \\
2001-4000 \mathrm{tl} \\
4000 \mathrm{tl} \text { üzeri }\end{array}$ & $\begin{array}{l}39 \\
62 \\
16\end{array}$ & $\begin{array}{l}33,3 \\
53,0 \\
13,7\end{array}$ \\
\hline $\begin{array}{l}\text { Yaşadığı yer } \\
\text { Kent merkezi } \\
\text { İlçe }\end{array}$ & $\begin{array}{l}113 \\
4\end{array}$ & $\begin{array}{c}96,6 \\
3,4 \\
\end{array}$ \\
\hline $\begin{array}{l}\text { Hipertansiyon tanı yılı } \\
1-5 \text { yıl } \\
6-10 \text { yıl } \\
\geq 11 \text { yıl }\end{array}$ & $\begin{array}{l}34 \\
41 \\
42\end{array}$ & $\begin{array}{l}29,1 \\
35,0 \\
35,9\end{array}$ \\
\hline $\begin{array}{l}\text { Hipertansiyon tedavisi } \\
\text { Monoterapi } \\
\text { Kombine Terapi }\end{array}$ & $\begin{array}{l}86 \\
31 \\
\end{array}$ & $\begin{array}{r}73,5 \\
26,5 \\
\end{array}$ \\
\hline $\begin{array}{l}\text { Ailede hipertansiyon hastalığı öyküsü } \\
\text { Evet } \\
\text { Hayır }\end{array}$ & $\begin{array}{l}84 \\
33 \\
\end{array}$ & $\begin{array}{l}71,8 \\
28,2 \\
\end{array}$ \\
\hline $\begin{array}{l}\text { Evde tansiyon aleti ile ölçüm } \\
\text { Evet } \\
\text { Hayır }\end{array}$ & $\begin{array}{r}19 \\
98 \\
\end{array}$ & $\begin{array}{l}16,2 \\
83,8\end{array}$ \\
\hline $\begin{array}{l}\text { Eşlik eden kronik hastalık } \\
\text { Evet } \\
\text { Hayır }\end{array}$ & $\begin{array}{l}79 \\
38 \\
\end{array}$ & $\begin{array}{l}67,5 \\
32,5 \\
\end{array}$ \\
\hline $\begin{array}{l}\text { Sigara kullanma durumu } \\
\text { Kullaniyor } \\
\text { Kullanmiyor }\end{array}$ & $\begin{array}{l}50 \\
67 \\
\end{array}$ & $\begin{array}{l}42,7 \\
57,3 \\
\end{array}$ \\
\hline $\begin{array}{l}\text { Alkol kullanma durumu } \\
\text { Evet } \\
\text { Hayır }\end{array}$ & $\begin{array}{l}6 \\
111 \\
\end{array}$ & $\begin{array}{l}5,1 \\
94,9 \\
\end{array}$ \\
\hline $\begin{array}{l}\text { Diyet tedavisine uyma } \\
\text { Hayır } \\
\text { Ara sira } \\
\text { Evet }\end{array}$ & $\begin{array}{l}49 \\
40 \\
28\end{array}$ & $\begin{array}{l}41,9 \\
34,2 \\
23,9\end{array}$ \\
\hline $\begin{array}{l}\text { Egzersiz yapma durumu } \\
\text { Evet } \\
\text { Hayır }\end{array}$ & $\begin{array}{l}46 \\
71 \\
\end{array}$ & $\begin{array}{r}60,7 \\
39,3 \\
\end{array}$ \\
\hline
\end{tabular}


Hastaların, antihipertansif ilaç tedavisine uyum

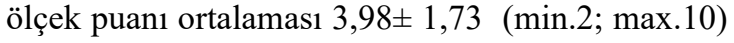
olarak tespit edilmiştir. Tablo 2'de antihipertansif ilaç uyum ölçek puanlarının demografik özellikler ve hastalık özellikleriyle karşılaştırılması yer almaktadır. İlaç uyum puanı açısından; kadınlarda, bekarlar da, eğitim düzeyi yüksek olanlarda, 11 y1lın üzerinde hipertansiyon öyküsü olanlarda, kombine antihipertansif ilaç tedavisi kullananlarda, ailede hipertansiyon öyküsü olanlarda, ek kronik hastalık varlığında ilaç uyum puanı daha düşük bulunmuş, ancak istatistiksel olarak anlamlılık tespit edilememiştir $(p=0,424 ; p=0,316 ; p=0,347$; $p=0,958 ; p=0,742, p=0,130 ; p=0,076)$. Sadece evde tansiyon aleti olup ölçüm yapanların, ilaç uyum puanları istatistiksel olarak anlamlı düzeyde daha düşük bulunmuştur( $\mathrm{p}=0,019)$.

\begin{tabular}{|c|c|c|c|}
\hline Değişkenler & İlaç uyumu & Test & $p$ \\
\hline $\begin{array}{l}\text { Cinsiyet }^{\mathbf{a}} \\
\text { Kadın } \\
\text { Erkek }\end{array}$ & $\begin{array}{l}3,83 \pm 1,50 \\
4,17 \pm 1,98 \\
\end{array}$ & $\mathrm{z}=-0,800$ & 0,424 \\
\hline $\begin{array}{l}\text { Medeni durum } \\
\text { Evli } \\
\text { Bekar }\end{array}$ & $\begin{array}{l}4,04 \pm 1,77 \\
3,73 \pm 1,57\end{array}$ & $z=-1,002$ & 0,316 \\
\hline $\begin{array}{l}\text { Ĕgitimb }^{\mathbf{b}} \\
\text { Ilkokul } \\
\text { Lise } \\
\text { Y. lisans/üniversite }\end{array}$ & $\begin{array}{l}4,08 \pm 1,65 \\
4,04 \pm 2,26 \\
3,47 \pm 0,94\end{array}$ & $\mathrm{kwh}=2,114$ & 0,347 \\
\hline $\begin{array}{l}\text { HT tanı yılı } \\
1-5 \text { yıl } \\
6-10 \text { yıl } \\
11 \text { yil ve üzeri }\end{array}$ & $\begin{array}{l}4,06 \pm 1,80 \\
4,02 \pm 1,85 \\
3,88 \pm 1,59\end{array}$ & $\mathrm{kwh}=0,086$ & 0,958 \\
\hline $\begin{array}{l}\text { Hipertansiyon tedavisi } \\
\text { Monoterapi } \\
\text { Kombine Terapi }\end{array}$ & $\begin{array}{l}4,00 \pm 1,80 \\
3,94 \pm 1,54\end{array}$ & $z=-0,329$ & 0,742 \\
\hline $\begin{array}{l}\text { Evde tansiyon aleti ile } \\
\text { ölçüma }^{\mathbf{a}} \\
\text { Evet } \\
\text { Hayır } \\
\end{array}$ & $\begin{array}{l}3,81 \pm 1,51 \\
4,89 \pm 2,47\end{array}$ & $z=-2,344$ & 0,019 \\
\hline $\begin{array}{l}\text { Ailede HT öyküsüa } \\
\text { Evet } \\
\text { Hayır }\end{array}$ & $\begin{array}{l}3,83 \pm 1,64 \\
4,36 \pm 1,93 \\
\end{array}$ & $\mathrm{z}=-1,515$ & 0,130 \\
\hline $\begin{array}{l}\text { Ek kronik hastalık } \\
\text { Evet } \\
\text { Hayır }\end{array}$ & $\begin{array}{l}3,76 \pm 1,50 \\
4,45 \pm 2,08 \\
\end{array}$ & $\mathrm{z}=-1,775$ & 0,076 \\
\hline $\begin{array}{l}\text { Sigara kullanma }^{\mathbf{a}} \\
\text { Evet } \\
\text { Hayır }\end{array}$ & $\begin{array}{l}4,00 \pm 1,78 \\
3,97 \pm 1,71 \\
\end{array}$ & $\mathrm{z}=-0,089$ & 0,929 \\
\hline $\begin{array}{l}\text { Egzersiz yapma }^{a} \\
\text { Evet } \\
\text { Hayir }\end{array}$ & $\begin{array}{l}4,11 \pm 1,88 \\
3,90 \pm 1,64\end{array}$ & $\mathrm{z}=-0,275$ & 0,783 \\
\hline $\begin{array}{l}\text { Diyete uyma } \\
\text { Evet } \\
\text { Ara sira } \\
\text { Hayır }\end{array}$ & $\begin{array}{l}4,11 \pm 1,72 \\
3,85 \pm 1,49 \\
4,02 \pm 1,94\end{array}$ & $\mathrm{kwh}=0,267$ & 0,875 \\
\hline
\end{tabular}

Bağımsız grup farklılıkların karşılaştırılmasında parametrik test varsayımları sağlanamadığından ikili grup karşılaştırmasında ${ }^{a}$ MannWhitney U testi ve üçlü grup karşılaştırmasında ${ }^{\mathrm{b}}$ Kruskal Wallis Varyans Analizi kullanıldı.

HT: Hipertansiyon

Katılımcıların sağlık algısı ortalama puanı $49,76 \pm 6,50$ olarak tespit edilmiş ve sağlık algısı puanı ile ilaç tedavisine uyum puanı arasında negatif yönde, zayıf düzeyde ilişki bulunmuştur $(\mathrm{r}=-0,211 ; \mathrm{p}=0,023)$. Yaşam kalitesi alt ölçeklerinden FBÖ ortalama puanı 43,59 $\pm 5,69$; MBÖ ortalama puanı $47,10 \pm 6,62$ bulunmuştur. İlaç tedavisine uyum puanı ile SF-12 alt ölçekleri arasında ilişki saptanamamıştır. Yine sayısal değişkenlerden yaş ve HT tanı yılı ile ilaç tedavisi uyum puanı arasında ilişki saptanamamıştır. Tablo 3 'te ilaç tedavisine uyumun yaş, HT tanı yılı, sağlık algısı ve yaşam kalitesi ile ilişkisi yer almaktadır. 


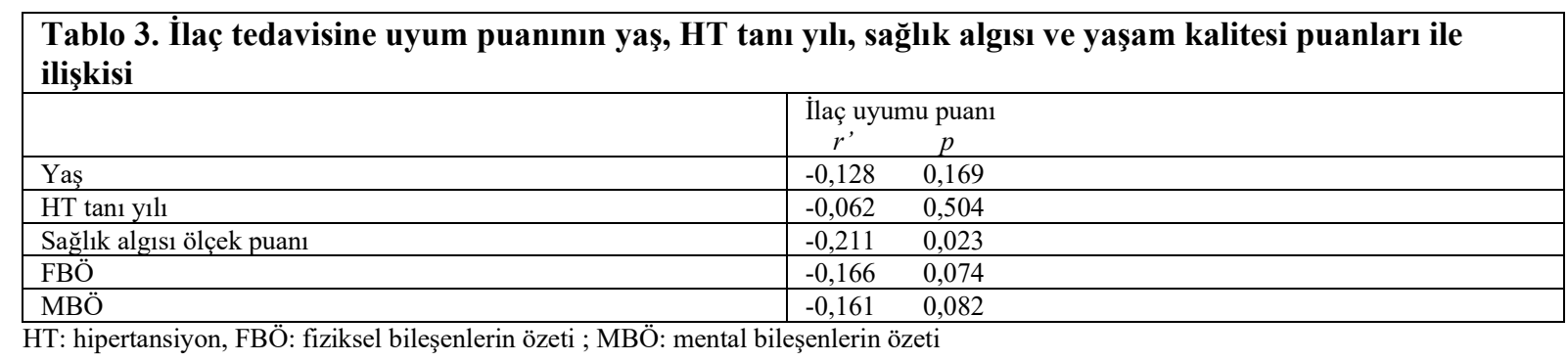

\section{TARTIŞMA}

Çalışmamızda, hipertansiyon hastalarında ilaç tedavisine uyumun $(\% 93,2)$ yüksek olduğu bulunmuştur. Literatürdeki çalışmalarda, antihipertansif tedaviye uyum oranları \%16,8-86,8 arasında değişmekte olup, çalışmamızda oldukça yüksek bulunmuştur. ${ }^{16-21}$ Uyum oranları arasındaki bu değişiklik, örnekleme yöntemlerindeki farklılıkla birlikte, standart bir uyum ölçüsünün olmamasıyla açıklanabilir. Ayrıca bizim çalışmamızın literatürdeki verilerden daha yüksek bulunmasını, çalışmanın yapıldığı bölgenin şehir merkezinde ve hekime ulaşımlarını açısından iyi bir bölge olmasına, düzenli hekim kontrollerini yaptırmasına bağlı olduğu düşünülmektedir. Bazı kılavuzlar, evde tansiyon ölçümü yapılmasının hipertansiyon kontrolünde önemli olduğunu belirtmektedir. ${ }^{10,22}$ Ev ölçümlerinin ilaç uyumunu, hekim kontrolü takiplerini ve tıbbi tedaviye aktif katılımı teşvik ettiği belirtilmektedir. ${ }^{23}$ Ayrıca, evde tansiyon ölçümlerinin sağlı davranışı ve hipertansiyon yönetimindeki değişiklikleri yönlendirmede yararlı olduğu gösterilmiştir. ${ }^{24}$

Hipertansiyon tedavisinde kan basınc1 kontrolü ana hedeftir. Literatürde yapılan çalışmalarda, tedaviye uyumlu olanların büyük bir kısmında kan basıncı kontrolünün sağlandığ1 bildirilmiştir. ${ }^{16,18,21,25-27}$ Benzer şekilde, ilaç uyumu iyi olanların kan basıncını yüksek oranda kontrol altında saptanmıştır.

Çalışmamızda, ilaç uyumu ile yaşam kalitesi arasında ilişki bulunmamıştır ancak Saleem ve ark. hipertansiyon hastalarında yaşam kalitesi ile ilaç uyumu arasında negatif yönde çok zayıf ilişki bulurken, yapılan diğer bir hipertansiyon hasta grubu çalışmasında ise pozitif yönde ilişki saptanmıştır. ${ }^{6,21,27}$ Literatürde diğer hasta gruplarında yapılan ilaç uyum çalışmalarında ise yaşam kalitesiyle pozitif yönde ilişki bulunduğu belirtilmektedir. ${ }^{28,29}$ Yaşam kalitesinin bir dizi faktörden etkilendiği ve sadece ilaç uyumu ile sınırlı olmadığı kabul edilmektedir. Buna ilaveten bu değişiklik, ilaç uyumu ve yaşam kalitesini değerlendirme yöntemlerindeki farklılıklara ve çalışma popülasyonlarına bağlanabilir.

Sağlık algısı, bireyin sağlığı geliştirici yaşam davranışları kazanmasını ve sürdürmesini sağlayan bir süreçtir. ${ }^{12}$ İlaç uyumu açısından Rajpura ve Nayak çalışmalarında, HT hastalarının büyük bir kısmının ilaç uyumunun kötü olduğunu ve ilaç uyumunda ilaçla ilgili inançların ve hastalık algısının önemli bir rol oynadığ ${ }_{1}$ belirlenlenmiştir. ${ }^{30}$ Literatürde diğer bir hastalık grubunda yapılan bir çalışmada da ilaç uyumuyla hastalık algısı arasında güçlü bir ilişki olduğu ve bu durumun ilaç uyumunda hastalık algısının önemli bir faktör olduğu belirtilmektedir. ${ }^{31}$ Literatüre benzer şekilde bulgularımız, ilaç uyumu iyi olanların sağlık algısı puanlarının daha yüksek olduğunu göstermektedir. İlaç tedavisine uyumla sosyo-demografik özellikler arasındaki ilişkiyi inceleyen literatürdeki çalışmalarda farklı sonuçlar mevcuttur. Bazı çalışmalar, yaşın ilaç uyumunu etkilemediğinden bahsederken ${ }^{17,19}$, yine başka çalışmalar genç yaş grubunda ilaç uyumunun daha kötü olduğunu belirtilmektedir. $\mathrm{Bu}$ durumun yaşlı bireylerin aksine, genç hastaların teşhis konulduktan sonra hipertansiyon için tedavi edilmesi gerektiğini ve düzenli ilaç kullanımı gereksinimi olduğunu düşünmediklerinden kaynaklandığı belirtilmektedir. ${ }^{18,19,26}$ Katılımcı grubumuzda yaş ve ilaç uyumu arasında ilişki bulunmamıştır. Yine çalışmamıza benzer şekilde, cinsiyetler ile ilaç uyumu arasında ilişki bulunmayan çalışmalar da mevcuttur. ${ }^{18-20,27}$ Medeni durum açısından, evli hastaların bekarlar kadar ilaç uyumları iyi iken, dul/ve boşanmış olanlarda ilaç uyumları düşük olarak bulan çalışmayla birlikte, ${ }^{19}$ çalışmamıza benzer şekilde medeni durumla ilaç uyumu arasında ilişki bulmayan çalışmalar da mevcuttur. ${ }^{17,20,27} \mathrm{Bu}$ nedenle sosyo-demografik özelliklerin tedaviye uyum konusunda farkl1lıklar gösterdiği ve etkileyen faktör olarak değerlendirilmesinin göreceli olabileceği düşünülmektedir.

\section{SONUÇ}

Sonuç olarak, kronik hastalıklarda tedaviye uyumu, yaşam kalitesi ve sağlık algısı gibi etkileyen birçok faktör vardır. Tedavinin başarısı veya başarısızlığ 1 değerlendirilirken bu faktörlerin özellikleri göz önünde bulundurulmalıdır. Ayrıca evde tansiyon ölçümlerinin ilaç uyumuna katkı sağladığ gösterilmiş olup evde tansiyon takiplerinin yapılması önerilmektedir. 
Çalışmanın bazı kısıtlılıkları vardır. İlk olarak, anketler ve ölçekler katılımcılara yüz yüze görüşme yoluyla uygulanmış olup bu durum hastalarda cevap yanlılı̆̆1 oluşturabilir. İkincisi bu tek merkezde ve az sayıda hastada yapılan bir çalışmadır. Türkiye'deki hipertansiyon prevalansını düşündüğümüzde, tüm hipertansiyon hastalarını temsil etmeyeceği düşünülmektedir.

\section{KAYNAKLAR}

1. Mills KT, Stefanescu A, He J. The global epidemiology of hypertension. Nat Rev Nephrol. 2020 Apr;16(4):223-37.

2. WHO Global status report on noncommunicable diseases 2014 [Internet]. WHO. World Health Organization; [a.yer 13 Nisan 2020]. Erişim adresi: http://www.who.int/nmh/publications/ncdstatus-report-2014/en/

3. Sengul S, Akpolat T, Erdem Y, Derici U, Arici $\mathrm{M}$, Sindel S, vd. Changes in hypertension prevalence, awareness, treatment, and control rates in Turkey from 2003 to 2012. J Hypertens. 2016;34(6):1208-17.

4. Arici M, Turgan C, Altun B, Sindel S, Erbay $B$, Derici U, vd. Hypertension incidence in Turkey (HinT): a population-based study. J Hypertens. 2010;28(2):240-4.

5. Cramer J. Cramer J. Medicine partnerships. Heart. 2003 May;89(suppl 2):ii19-21.

6. Saleem F, Hassali MA, Shafie AA, Awad GA, Atif $\mathrm{M}$, ul Haq $\mathrm{N}$, vd. Does treatment adherence correlates with health related quality of life? Findings from a cross sectional study. BMC Public Health. 2012 Apr;12:318.

7. Önal AE, Erbil S, Gürtekin B, Ayvaz Ö, Özel $\mathrm{S}$, Cevizci S, Güngör $\mathrm{G}$. İki ilköğretim okulunda öğrencilerin kendi sağlıklarını algılama düzeyi ve bildikleri sağlık sorunları". Nobel Medicus, 2009;5(2): 24-48.

8. Al-Noumani $\mathrm{H}, \mathrm{Wu} \mathrm{JR}$, Barksdale $\mathrm{D}$, Alkhasawneh E, Knafl G, Sherwood G. Relationship between medication adherence and health beliefs among patients with hypertension in Oman: Pilot study. Sultan Qaboos University Medical Journal. 2017 Aug;17(3):e329.

9. Yue Z, Bin W, Weilin Q, Aifang Y. Effect of medication adherence on blood pressure control and risk factors for antihypertensive medication adherence. J Eval Clin Pract. 2015 Feb;21(1):166-72.

10. ESC/ESH Arterial Hypertension (Management of) Guidelines 2018 [Internet]. [a.yer 14 Nisan 2020]. Erişim adresi: https://www.escardio.org/Guidelines/ClinicalPractice-Guidelines/Arterial-HypertensionManagement-of,

11. Morisky DE, Green LW, Levine DM. Concurrent and predictive validity of a selfreported measure of medication adherence Medical care. 1986:67-74.

12. Demirezen E. Türkiye'de ve Almanya'da yaşayan antihipertansif ilaç kullanan Türklerde ilaç tedavisine uyum. İstanbul Üniversitesi Sağlık Bilimleri Enstitüsü, Hemşirelik Programı Doktora Tezi, İstanbul, 2006: 30-31.

13. Kadıŏlu H, Yıldız A. Sağlık Algısı Ölçeği'nin Türkçe çevriminin geçerlilik ve güvenilirliği. Turkiye Klinikleri Journal of Medical Sciences. 2012;32(1):47-53.

14. Kilic C. General health questionnaire: Reliability and validity study. Turkish Journal of Psychiatry. 1996;7(1):3-9.

15. Kilic C, Rezaki M, Rezaki B, et al. General health questionnaire (GHQ12 \& GHQ28): Psychometric properties and factor structure of the scales in a Turkish primary care sample. Social Psychiatry and Psychiatric Epidemiology. 1997;32(6):327-331.

16. Anadol Z, Dişcigil G. Hipertansif hastalarda tedavi uyumunu etkileyen faktörler. Turkiye Klinikleri J Cardiovasc Sci. 2009;21(2):18490.

17. Mert H, Kuruoğlu E. Multidisipliner bir özel çalışma modülü araştırması: Hipertansiyon hastalarının tedaviye uyumlarının incelenmesi. Turkish Journal of Family Practice/Türkiye Aile Hekimligi Dergisi. 2011 Jan 1;15(1).

18. Al-Ramahi R. Adherence to medications and associated factors: A cross-sectional study among Palestinian hypertensive patients. J Epidemiol Glob Health. 2015 Jun;5(2):125-32.

19. Alhaddad IA, Hamoui O, Hammoudeh A, Mallat S. Treatment adherence and quality of life in patients on antihypertensive medications in a Middle Eastern population: adherence. Vasc Health Risk Manag. 2016;12:407-13. 
20. Arslan DE, Akça NK. Kırsal alanda yaşayan hipertansiyon hastalarının ilaç tedavisine uyumları. Bozok Tip Dergisi, 2019;10(1):5562.

21. Zyoud SH, Al-Jabi SW, Sweileh WM, Wildali AH, Saleem HM, Aysa HA, vd. Health-related quality of life associated with treatment adherence in patients with hypertension: a cross-sectional study. Int J Cardiol. 2013 Oct;168(3):2981-3.

22. Shimamoto K, Ando K, Fujita T, Hasebe N, Higaki J, Horiuchi M, Imai Y, Imaizumi $\mathrm{T}$, Ishimitsu $\mathrm{T}$, Ito $\mathrm{M}$, et al. Japanese society of hypertension committee for guidelines for the management of hypertension. The Japanese society of hypertension guidelines for the management of hypertension (JSH 2014). Hypertens Res. 2014;37:253-390. doi:10.1038/hr.2014.20.

23. Imai Y, Ohkubo T, Kikuya M, Hashimoto J. Practical aspect of monitoring hypertension based on self-measured blood pressure at home. Intern Med. 2004;43:771-78.

24. Cheng, Hao-Min, et al. Asian management of hypertension: Current status, home blood pressure, and specific concerns in Taiwan. The Journal of Clinical Hypertension. 2020;22:511-514.

25. Waeber B. Treatment strategy to control blood pressure optimally in hypertensive patients. Blood Press. 2001;10(2):62-73.
26. Yiannakopoulou EC, Papadopulos JS, Cokkinos DV, Mountokalakis TD. Adherence to antihypertensive treatment: a critical factor for blood pressure control. Eur J Cardiovasc Prev Rehabil. 2005 Jun;12(3):243-9.

27. Park NH, Song MS, Shin SY, Jeong J-H, Lee HY. The effects of medication adherence and health literacy on health-related quality of life in older people with hypertension. Int J Older People Nurs. 2018;13(3):e12196.

28. Carballo E, Cadarso-Suárez C, Carrera I, Fraga J, de la Fuente J, Ocampo A, vd. Assessing relationships between health-related quality of life and adherence to antiretroviral therapy. Qual Life Res. 2004;13(3):587-99.

29. Takemura, Masaya, et al. Repeated instruction on inhalation technique improves adherence to the therapeutic regimen in asthma. Journal of Asthma. 2010 Mar;47(2):202-208.

30. Rajpura JR, Nayak R. Role of illness perceptions and medication beliefs on medication compliance of elderly hypertensive cohorts. J Pharm Pract. 2014;27(1):19-24.

31. Haddad C, Hallit S, Salhab M, Hajj A, Sarkis A, Ayoub EN, vd. Association Between Adherence to Statins, Illness Perception, Treatment Satisfaction, and Quality of Life among Lebanese patients. J Cardiovasc Pharmacol Ther. 2018;23(5):414-22. 